\title{
CYCLIC DWELL FATIGUE BEHAVIOUR OF SINGLE CRYSTAL NI-BASE SUPERALLOYS WITH/WITHOUT RHENIUM
}

\author{
S. Yandt ${ }^{1}, \mathrm{X}-\mathrm{J} . \mathrm{Wu}^{1}, \mathrm{~N} . \mathrm{Tsuno}^{2}$ and A. Sato ${ }^{2}$ \\ ${ }^{1}$ National Research Council Canada, Institute for Aerospace Research; Ottawa Ontario, K1A 0R6, Canada \\ ${ }^{2}$ IHI Corporation; 1 Shin-Nakahara-cho, Isogo-ku,Yokohama, Kanagawa 235-8501, Japan
}

Keywords: low-cycle fatigue, creep-fatigue, single crystal, superalloy

\begin{abstract}
In this study, compressive dwell (C-D) and no-dwell (N-D) lowcycle fatigue (LCF) behaviours of several single crystal Ni-base superalloys, including CMSX-4, LSC-11 and LSC-15, were studied under strain-controlled zero-compression $\left(\mathrm{R}_{\varepsilon}=-\infty\right)$ loading at $1100^{\circ} \mathrm{C}$. LSC-11 and LSC-15 are new alloys developed by IHI Corporation, Japan with 0.8 wt $\%$ Re and without $\mathrm{Re}$ addition, respectively, as reduced-cost alternatives to the second generation single crystal Ni-base superalloys. The fatigue experiments were conducted with or without a two-minute dwell (hold) in compression and total strain ranges of $0.7 \%, 0.6 \%$ and $0.5 \%$ on uncoated specimens in the [001] orientation. Examination of the cyclic stress-strain behavior revealed that the initially compressive mean stress relaxed to approximately zero stress in N-D tests, while compressive hold resulted in the development of a tensile mean stress during C-D fatigue. Cyclic stress softening was observed under all test conditions. Microstructural analysis of tested specimens showed that N-D fatigue promoted isotropic coarsening of the $\gamma$ ' precipitates, while C-D loading resulted in the formation of discontinuous $\gamma^{\prime}$ rafting parallel to the loading direction. Fatigue cracks initiated from the specimen surface from regions of localized oxide attack. All alloys were compressive dwell sensitive. C-D fatigue lives were $4-15 \times$ shorter than N-D when the same alloys were considered. CMSX-4 exhibited 1.5-3 $\times$ N-D fatigue life advantage over alloys LSC-11 and LSC-15. Under C-D fatigue the life advantage of CMSX-4 was 20-50\% greater than alloys LSC-11 and LSC- 15 . The differences in these behaviours could be attributed to $\mathrm{Re}$ content and oxidation.
\end{abstract}

\section{Introduction}

The second and later generations of single-crystal Ni-base superalloys are hallmarked by the increasing content of Rhenium (Re), owing to its strong beneficial effect on the alloys high temperature mechanical properties. The commercial second generation single crystal alloys such as PWA1484 [1], CMSX-4 [2] and René N5 [3], contain up to 3 wt $\%$ Re while the third and newer generations contain Re concentration up to $6 \mathrm{wt} \%$ [4-6]. However, the increased demand of Re, drawn from limited supply sources, has driven the price up such that Re constitutes the majority of the raw material cost. For a wide range of industrial applications where cost-reduction is a constant driver, low-cost single crystal $\mathrm{Ni}$-base superalloys that have comparable high temperature properties to Re-containing single crystal superalloys may become more attractive.

Several low-Re or Re-free single crystal Ni-base superalloys have been developed. For example, DD6 by BIAM [7], which contains $2 \mathrm{wt} \%$ Re; Alloy MC2, developed by Onera [8], which contains no Re; and more recently, alloys LSC-11 and LSC-15, developed by IHI Corporation, which contains 0.8 wt $\% \mathrm{Re}$ and no $\mathrm{Re}$ addition, respectively. These alloys were assigned as costreduction alternatives to the second generation single crystal $\mathrm{Ni}$ base superalloys. They can exhibit creep rupture strength comparable to or sometimes exceeding the second generation alloys [7-9]. For example, MC2 claims to offer a creep-rupture advantage greater than $40^{\circ} \mathrm{C}$ above the first generation alloy CMSX-2 at temperatures above $1000^{\circ} \mathrm{C}$ [8]. Although creep resistance is the primary consideration in the design of single crystal Ni-base superalloys, fatigue performance, particularly with dwell, is usually a durability concern for service [10], since it mimics the thermal fatigue condition that a blade would experience during transient operations of gas turbine engines. To the authors' best knowledge, compressive dwell fatigue behavior of single crystal Ni-base superalloys has not been studied extensively.

In general, creep/fatigue and oxidation interactions can result in complicated failure mechanisms in uncoated single crystal alloys when subjected to cyclic loading at high temperatures. It has been reported that at temperatures below $950^{\circ} \mathrm{C}$ fatigue cracks mostly initiate at surface/subsurface micropores, or by oxidation at the specimen surface [11]. At higher temperatures $\left(\mathrm{T}>950^{\circ} \mathrm{C}\right)$ fatigue cracks initiate from regions of localized surface oxidation attack [11,12]. Furthermore, during prolonged exposure at elevated temperatures $\left(\mathrm{T}>900^{\circ} \mathrm{C}\right)$ under mechanical loading, the initially cuboidal $\gamma^{\prime}$ precipitates in single-crystal nickel-base superalloys can coarsen, either isotropically or directionally. It has been commonly observed that directional coarsening, or rafting, occurs when single-crystal superalloys are subjected to stress at elevated temperatures. Rafting of the $\gamma-\gamma$ ' microstructure has been primarily studied under constant load creep conditions [13-15]. Rafting can also occur under TMF loading conditions [16] or during strain-controlled isothermal fatigue tests incorporating tensile or compressive dwell periods [10]. Progressive $\gamma$ ' coarsening, whether directional or isotropic in nature, can result in significant changes in the cyclic stress-strain response of the material and hence the fatigue failure mechanism [17].

In this investigation, compressive dwell and no-dwell low-cycle fatigue (LCF) of LSC-11 and LSC-15 were studied, in comparison with CMSX-4, a second generation alloy. The fatigue tests were performed on uncoated specimens in [001] orientation at $1100^{\circ} \mathrm{C}$. The purpose of the study was to evaluate the compressive fatigue performance of low-Re or Re-free single crystal Ni-base superalloys, understanding the effects of composition and microstructure on such fatigue behavior and identifying the predominant factors affecting the LCF life. This knowledge can be used to improve alloy design. 


\section{Materials and Procedures}

The alloys considered in this investigation are LSC-11, LSC-15 and CMSX-4. The nominal chemical compositions of these alloys are summarized in Table I. Solid cylindrical fatigue specimens with a gage length of $18 \mathrm{~mm}$ and gage section diameter of $6 \mathrm{~mm}$ were provided by IHI Corporation. The specimens were machined from heat treated cylindrical single-crystal bars with the [001] direction aligned within $7.5^{\circ}$ of the fatigue specimen loading direction. The solution, precipitation and aging heat treatments were conducted in a vacuum furnace. Details of the precipitation and aging heat treatments applied to the alloys are provided in Table II.

Table I. Nominal chemical compositions of LSC-11, LSC-15 and CMSX-4 (wt\%)

\begin{tabular}{|l|l|l|l|l|l|l|l|l|l|l|}
\hline Alloy & $\mathrm{Co}$ & $\mathrm{Cr}$ & $\mathrm{Mo}$ & $\mathrm{W}$ & $\mathrm{Al}$ & $\mathrm{Ti}$ & $\mathrm{Ta}$ & $\mathrm{Hf}$ & $\mathrm{Re}$ & $\mathrm{Ni}$ \\
\hline $\begin{array}{l}\text { LSC- } \\
11\end{array}$ & 8.0 & 7.0 & 1.8 & 8.2 & 5.4 & 1.2 & 6.2 & 0.1 & 0.8 & $\mathrm{Bal}$ \\
\hline $\begin{array}{l}\text { LSC- } \\
15\end{array}$ & 6.0 & 7.0 & 1.5 & 10 & 6.0 & - & 5.5 & 0.1 & - & $\mathrm{Bal}$ \\
\hline $\begin{array}{l}\text { CMSX } \\
-4\end{array}$ & 9.0 & 6.5 & 0.6 & 6.0 & 5.6 & 1.0 & 6.5 & 0.1 & 3.0 & $\mathrm{Bal}$ \\
\hline
\end{tabular}

Table II. Precipitation and aging heat treatment details

\begin{tabular}{|l|l|l|}
\hline Alloy & Precipitation & Aging \\
\hline LSC-11 & $1100^{\circ} \mathrm{C} / 4 \mathrm{hr}$ GFC $*$ & $870^{\circ} \mathrm{C} / 20 \mathrm{hr}$ GFC \\
\hline LSC-15 & $1100^{\circ} \mathrm{C} / 4 \mathrm{hr}$ GFC & $870^{\circ} \mathrm{C} / 20 \mathrm{hr}$ GFC \\
\hline CMSX-4 & $1140^{\circ} \mathrm{C} / 4 \mathrm{hr}$ GFC & $870^{\circ} \mathrm{C} / 20 \mathrm{hr}$ GFC \\
\hline
\end{tabular}

*GFC: gas fan cooling

The fatigue experiments were conducted in an MTS 810 computer-controlled servo-hydraulic test machine under total strain control at $1100^{\circ} \mathrm{C}$ using a zero-compression $\left(\mathrm{R}_{\varepsilon}=-\infty\right)$ triangular waveform at a constant total strain rate of $4 \times 10^{-3} \mathrm{~s}^{-1}$. Three strain ranges $0.7 \%, 0.6 \%$ and $0.5 \%$ were selected for evaluation. Dwell-fatigue tests were performed with 120 second hold at the maximum strain in compression to investigate the creep-fatigue behaviour. The total strain was measured and controlled using an air-cooled axial extensometer with a gage length of $12 \mathrm{~mm}$. Specimens were heated using high frequency induction heating and an infrared pyrometer was used for closedloop control of the temperature. Fatigue tests were terminated after the tensile stress amplitude dropped 20\% from the stabilized cyclic tensile stress response or specimen separation, whichever occurred first.

Microstructural characterization, using scanning electron (SEM) and optical microscopy, was performed on transverse and longitudinal metallographic sections prepared from fully heat treated single crystal bars and tested fatigue specimens. Specimens for SEM analysis were mounted in a conductive thermal setting resin and polished using standard metallographic sample preparation techniques. To reveal the size and morphology of the $\gamma^{\prime}$ precipitate structure in the heat treated condition and after fatigue testing, metallographic samples were electo-chemical etched in a solution containing $48 \mathrm{ml} \mathrm{H}_{2} \mathrm{SO}_{4}, 12 \mathrm{ml} \mathrm{H}_{3} \mathrm{PO}_{4}, 40 \mathrm{ml}$ $\mathrm{HNO}_{3}$, and $100 \mathrm{ml} \mathrm{H}_{2} \mathrm{O}$ for $1-2$ seconds at 6.5 volts.

\section{Results}

\section{Microstructure of Fully Heat Treated Materials}

The microstructures of LSC-11, LSC-15 and CMSX-4 are shown in Figures $1 \mathrm{a}-\mathrm{c}$, respectively. The microstructure of all three alloys consisted of homogeneous distribution of cuboidal primary $\gamma$ ' precipitates aligned along the $\langle 100\rangle$ directions. The mean $\gamma$ ' edge length was approximately $0.45 \mu \mathrm{m}$ in alloys LSC-11 and CMSX-4, while precipitates in LSC-15 were slightly larger at approximately $0.70 \mu \mathrm{m}$. The volume fraction of primary $\gamma^{\prime}$ was similar in all three alloys, approximately $70 \mathrm{vol}$. \%. Ultrafine secondary (aging) $\gamma^{\prime}$ precipitates, with an edge length of approximately $50 \mathrm{~nm}$, were observed in the $\gamma$-channels in all three alloys, as shown in Figure 1d. Residual eutectic $\gamma-\gamma^{\prime}$ was not observed in the fully heat treated materials.

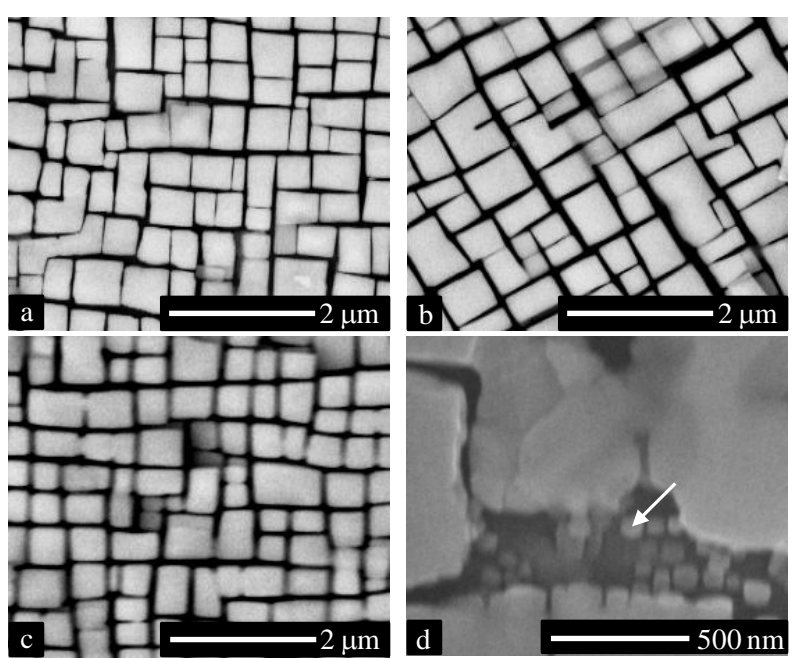

Figure 1. Fully heat treated primary $\gamma^{\prime}$ microstructures of a) LSC11, b) LSC-15 and c) CMSX-4. d) Secondary $\gamma^{\prime}$ precipitates (arrow) precipitated during aging heat treatment.

\section{Monotonic and Cyclic Stress-Strain Response}

The stress-strain response during the first cycle of N-D and C-D fatigue tests with $0.7 \%$ strain range in compression are shown in Figure $2 \mathrm{a}$ and $2 \mathrm{~b}$, respectively. The first half cycle, which represents monotonic load application from zero to the maximum compressive strain amplitude, was similar for N-D and C-D tests conducted at the same total strain range. The compressive yield strength for the alloys is summarized in Table III. The compressive yield strength of CMSX-4 was higher than alloys LSC-11 and LSC-15 at the test temperature of $1100^{\circ} \mathrm{C}$. Interestingly, the trend appeared to coincide with the increase of the $\operatorname{Re}$ content in these alloys, i.e. alloys containing higher concentrations of Re exhibited higher compressive yield strength. 

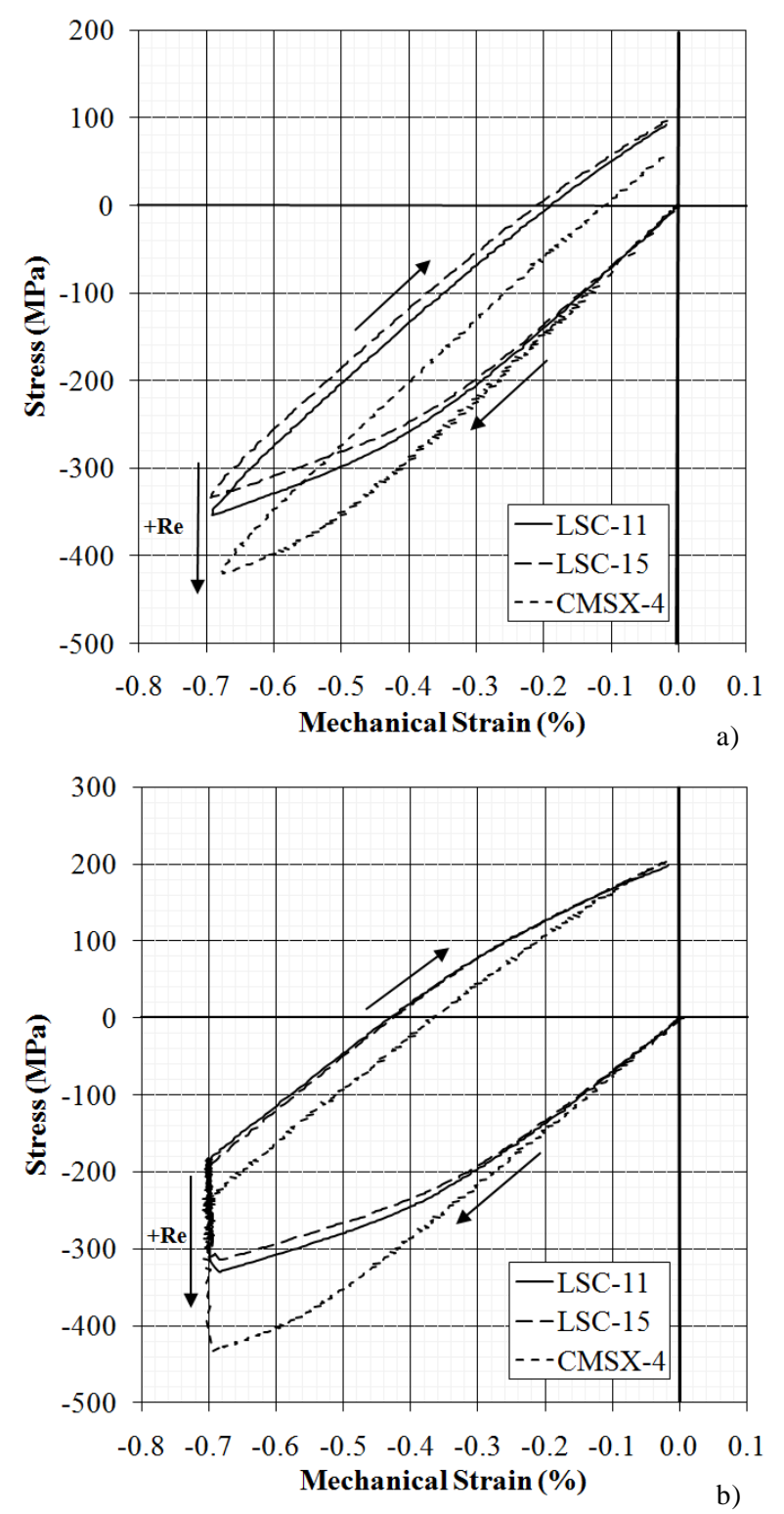

Figure 2. First cycle stress-strain hysteresis loops at $\mathrm{T}=1100^{\circ} \mathrm{C}$ and $\Delta \varepsilon=0.7 \%$ for a) non-dwell and b) 2 minute dwell at maximum compressive strain amplitude.

Table III. Compressive $0.2 \%$ offset yield strength

\begin{tabular}{|l|c|}
\hline Alloy & $\begin{array}{l}\text { Compressive 0.2\% } \\
\text { Offset Yield (MPa) }\end{array}$ \\
\hline LSC-11 & -352 \\
\hline LSC-15 & -326 \\
\hline CMSX-4 & -450 \\
\hline
\end{tabular}
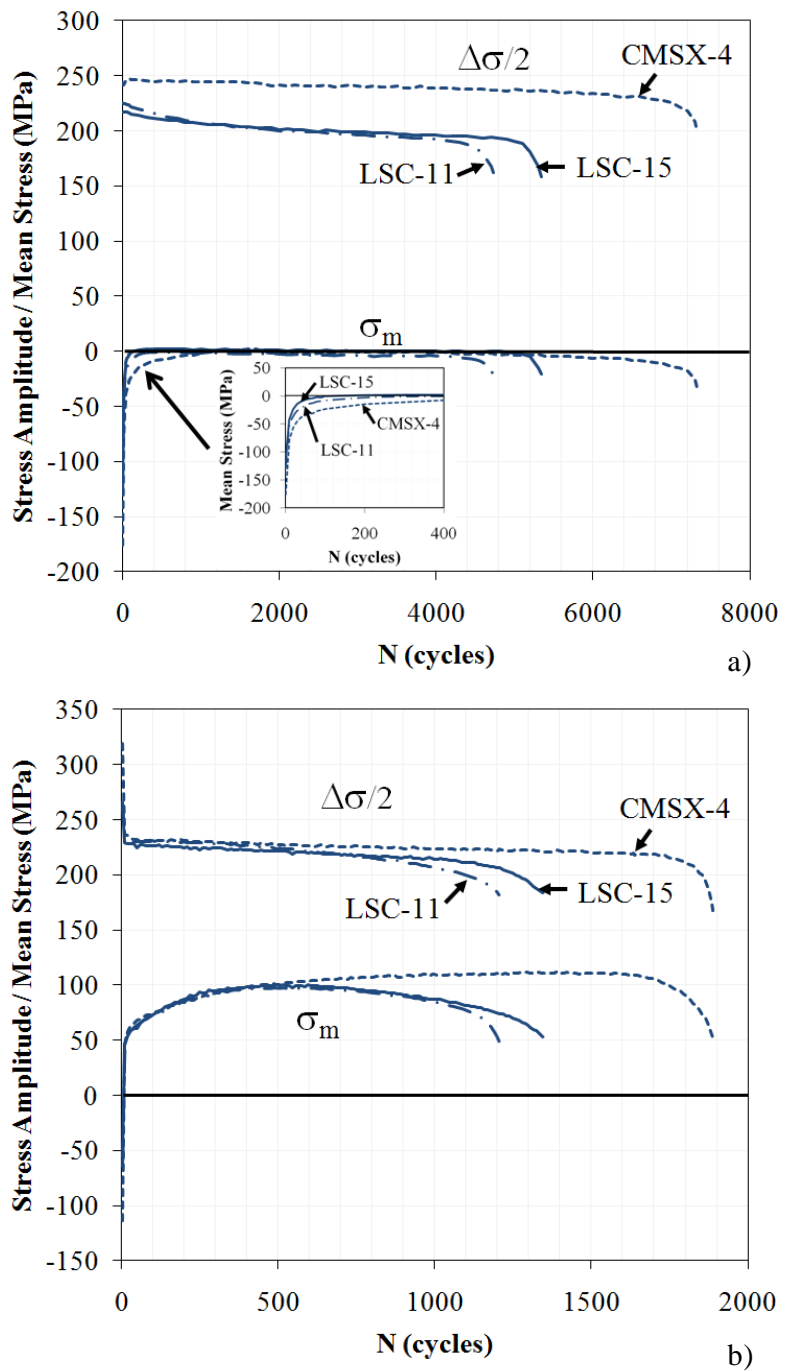

Figure 3. Cyclic stress response during a) N-D and b) C-D fatigue tests conducted $\mathrm{T}=1100^{\circ} \mathrm{C}$ and $\Delta \varepsilon=0.7 \%$. Note: $\Delta \sigma / 2$ is the stress amplitude and $\sigma_{\mathrm{m}}$ represents the mean stress.

The feature differentiating the first cycle stress-strain responses of $\mathrm{N}-\mathrm{D}$ and C-D tests was the substantial stress relaxation that occurred during C-D as a result of creep deformation during the 2 minute hold in compression. During reversal from the compressive strain limit, plasticity that occurred during the first half of the loading cycle was partially reversed by plasticity in tension, which reduced the kinematic hardening of the material during subsequent fatigue cycles. This caused the mean stress to reduce to nearly zero during N-D fatigue tests, but in C-D tests, because of creep strain accumulation during the dwell periods, the mean stress changed from initially negative to positive.

The evolution of the cyclic stress amplitude and mean stress for $\mathrm{N}-\mathrm{D}$ and C-D tests conducted at total strain range of $0.7 \%$ are shown in Figures 3 a) and b), respectively. The trend was similar 
for tests conducted at lower strain ranges. For N-D fatigue loading the initially compressive mean stress relaxed towards zero stress within the first $20 \%$ of the fatigue life. The compressive mean stress relaxed more quickly in LSC-11 and LSC-15 than CMSX-4, as shown in the Figure 3a) (inset). Similar mean stress relaxation behavior was observed in N-D tests at all strain ranges considered in this investigation. For C-D fatigue tests (Figure $3 \mathrm{~b}$ ) the stress amplitude quickly decreased and the mean stress transitioned from compressive to tensile after the first 5-10 fatigue cycles, depending on the applied strain range. Both N-D and C-D fatigue cycling resulted in cyclic stress softening in all three alloys. Cyclic stress softening during N-D fatigue was higher in alloys LSC-11 and LSC-15 than CMSX-4. Under C-D loading all three alloys exhibited higher cyclic stress softening than under N-D fatigue. Alloy LSC-11 also exhibited higher cyclic stress softening than alloy LSC-15 under N-D and C-D fatigue cycling, when comparing similar total strain amplitudes.

\section{Fatigue Life}

Experimental results for the cyclic life under N-D and C-D fatigue are presented in Figure 4. In terms of total strain range (Figure 4a) C-D fatigue resulted in a substantial life debit of $4-15 \times$ as compared to N-D fatigue, depending on the alloy considered and the applied total strain range. Under N-D fatigue loading CMSX-4 exhibited 1.5-3× life advantage over alloys LSC-11 and LSC- 15 . The fatigue life advantage of CMSX-4 over alloys LSC-11 and LSC-15 was $20-50 \%$ under C-D loading. When comparing fatigue lives on the basis of mid-life inelastic strain range (Figure $4 b$ ), no satisfactory correlation with fatigue life could be achieved. However, it is apparent that the inelastic strain ranges were higher for alloys LSC-11 and LSC-15 than CMSX-4 under N-D fatigue. On the other hand, the maximum tensile stress response from the mid-life cycle did provide a satisfactory correlation with fatigue life, as shown in Figure 4c. It is also apparent that the maximum tensile stress at mid-life was higher for C-D than N-D tests.

\section{Microstructural Evolution During LCF}

After fatigue testing specimens were sectioned longitudinally to examine the $\gamma-\gamma$ ' microstructures. Representative micrographs showing the postmortem microstructures for alloys LSC-15 and CMSX-4 subjected to N-D and C-D fatigue loading are shown in Figure 5. The $\gamma-\gamma$ ' microstructure evolution in alloy LSC-11 was similar to LSC-15. Comparing the $\gamma-\gamma$ ' microstructures before (Figure 1) and after fatigue testing (Figure 5), it is apparent that the $\gamma^{\prime}$ precipitates coarsened and coalesced isotropically without a preferred direction under N-D fatigue loading (Figures 5a and 5b). C-D loading promoted the formation of discontinuous rafts oriented parallel to the direction of loading (Figures $5 \mathrm{c}$ and $5 \mathrm{~d}$ ). Qualitatively, there was a higher degree of $\gamma^{\prime}$ coarsening in alloys LSC-11 and LSC-15 than in CMSX-4 under N-D fatigue loading when comparing $\gamma-\gamma^{\prime}$ microstructures from identical test conditions. The degree of $\gamma-\gamma$ ' microstructural change under both N-D and C-D fatigue loading also appeared to be dependent on the elapsed exposure time at $1100^{\circ} \mathrm{C}$. Fatigue tests conducted at lower strain ranges, i.e. test conditions with longer fatigue lives, showed a greater degree $\gamma-\gamma^{\prime}$ microstructural evolution than shorter duration fatigue tests due to longer elapsed exposure times at high temperature.

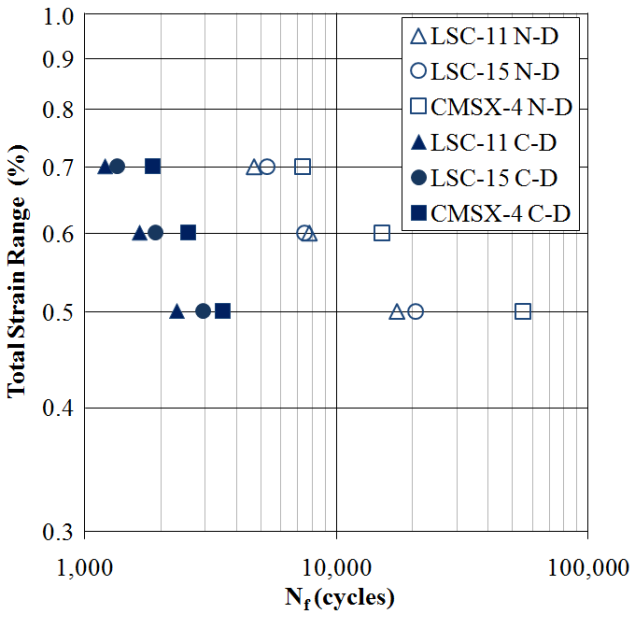

a)
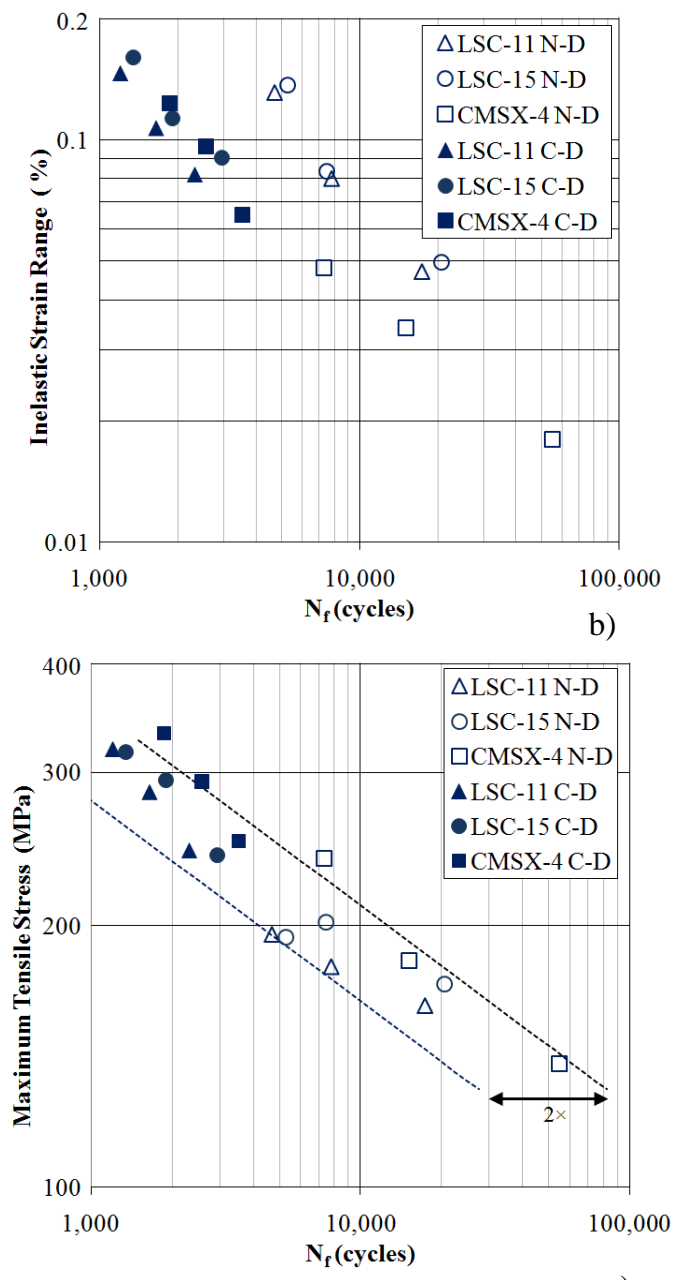

c)

Figure 4. Low cycle fatigue lives correlated with a) total strain, b) inelastic strain and c) maximum tensile stress. 


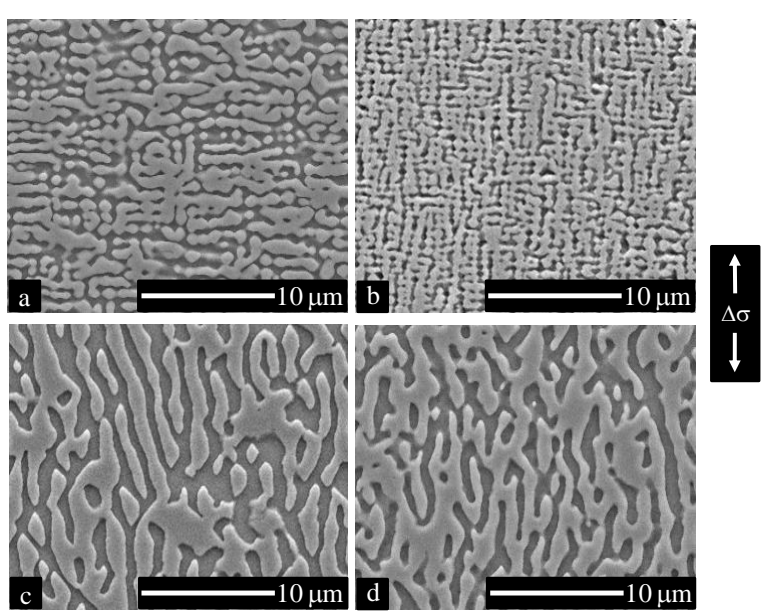

Figure 5. The $\gamma-\gamma$ ' microstructure after fatigue testing: a) LSC-15 N-D $\Delta \varepsilon=0.5 \%$, b) CMSX-4 N-D $\Delta \varepsilon=0.5 \%$, d) LSC-15 C-D $\Delta \varepsilon$ $=0.5 \%$ and d) CMSX-4 C-D $\Delta \varepsilon=0.5 \%$. Note: microstructural evolution of LSC-11 was similar to LSC-15.

\section{Fractography}

After fatigue testing both the fatigue fracture surface and the specimen gage section were examined using optical and scanning electron microscopy to elucidate the mechanisms of crack formation and propagation. A representative fracture surface is shown in Figure 6. The fracture surfaces for both N-D and C-D fatigue tests consisted of a single dominant fatigue crack formed by the coalescence of several smaller fatigue cracks that initiated from the specimen surface (Figure 6a). The fracture surfaces were heavily oxidized obscuring the details of the crack initiation sites. In general, fatigue cracks in N-D and C-D specimens were observed to be initially semi-elliptical in shape and oriented normal to the specimen loading direction up to a depth of approximately $1 \mathrm{~mm}$, but transitioned to one or more $\{111\}$ crystallographic planes at larger crack sizes or after several smaller cracks coalesced (Figure 6b).

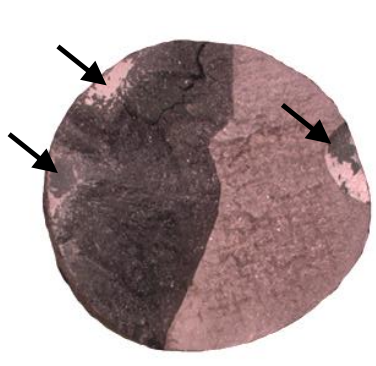

a)

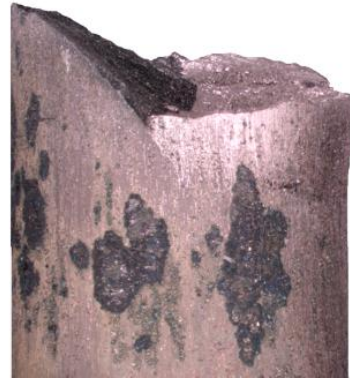

b)
Figure 6. Representative fracture surface features for N-D and CD fatigue tests: a) fracture surface with multiple crack initiation sites (arrows), and b) profile view of fatigue specimen. LSC-15 N$\mathrm{D} \Delta \varepsilon=0.7 \%$.

In addition to examining the characteristics of the dominant fatigue crack, observations of the specimen gage section revealed numerous surface-connected secondary fatigue cracks, examples of which are shown in Figure 7a. Qualitatively, the occurrence of secondary fatigue cracks appeared to be higher in specimens subjected to C-D fatigue cycling. Fatigue specimens were sectioned longitudinally to examine the secondary fatigue cracks in greater detail. An SEM micrograph showing a secondary fatigue crack is shown in Figure 7b. Generalized surface oxidation of the exposed surface of the specimen is apparent. Adjacent to the surface oxide layer is the substrate material which has been depleted of $\gamma^{\prime}$ precipitates. A localized region of oxide attack (oxide spike) is also apparent from which a secondary fatigue crack has initiated. The secondary fatigue crack tip and wake were also heavily oxidized and the material surrounding the fatigue crack was also depleted of $\gamma^{\prime}$ precipitates. The width of the oxide layer and $\gamma^{\prime}$ depleted zone decreased along the crack length from approximately $10 \mu \mathrm{m}$ near the surface to less than $1 \mu \mathrm{m}$ near the crack tip.

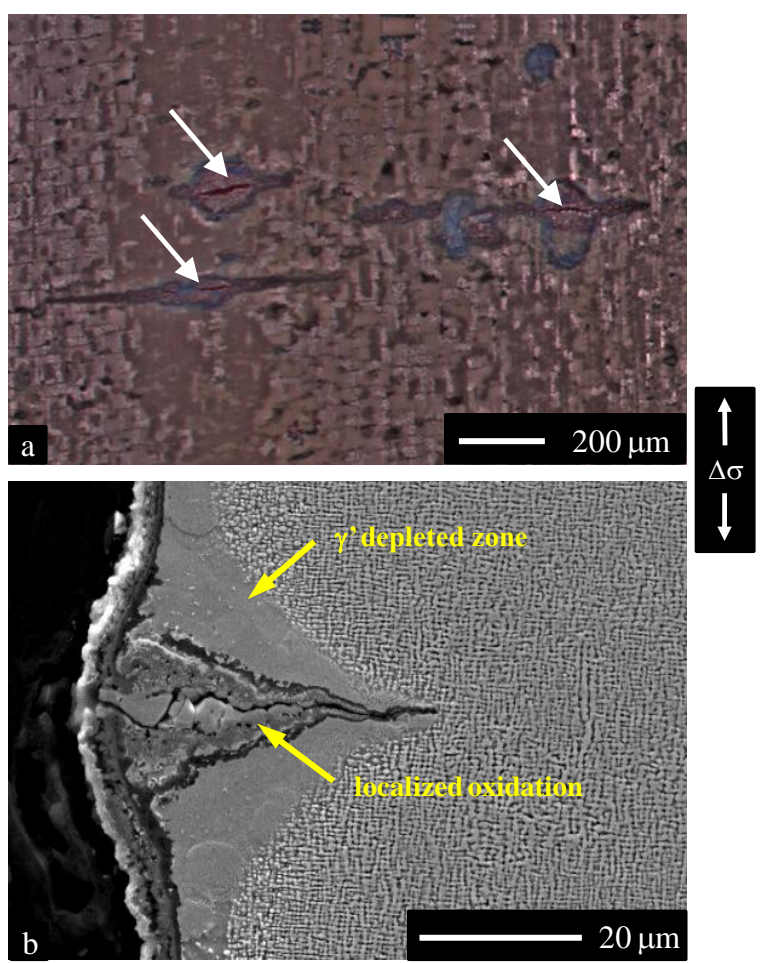

Figure 7. a) Optical micrograph showing secondary fatigue cracks (arrows) within the specimen gage section and b) SEM micrograph showing a surface crack forming from a localized region of oxide attack. LSC-11 C-D $\Delta \varepsilon=0.7 \%$.

\section{Discussion}

It is well understood that the mechanical properties of single crystal superalloys depends on the $\gamma-\gamma^{\prime}$ microstructure. Plastic deformation in these alloys occurs either by dislocations shearing the $\gamma^{\prime}$ precipitates, or by strain-rate dependent $\gamma^{\prime}$-bypass via thermally activated glide and climb mechanisms in the $\gamma$-matrix phase. At high temperature $\left(\mathrm{T}>950^{\circ} \mathrm{C}\right)$, deformation mostly occurs by the latter mechanism [17-19], where the mobility of 
dislocations in the $\gamma$-matrix and the $\gamma^{\prime}$ volume fraction dictates the monotonic and cyclic deformation response.

The $\gamma^{\prime}$ volume fraction for the alloys considered in this investigation were approximately $70 \mathrm{vol} \%$ at ambient temperature, it reduced to $44-46 \mathrm{vol} \%$ at the test temperature of $1100^{\circ} \mathrm{C}$ after prolonged exposure. Since the $\gamma^{\prime}$ volume fraction for all three alloys was similar, and so was the total refractory element content, the higher compressive yield strength of CMSX4 appeared to be attributed to the higher Re content of this alloy. It is understood that $\mathrm{Re}$ is a potent solid solution strengthener of the $\gamma$-matrix and has the lowest diffusion rate among all the refractory elements used in superalloys [20]. Therefore, it is anticipated that Re addition would reduce the climb rate of dislocations in the $\gamma$ matrix, and thus improve the high temperature yield properties, which explains the higher compressive yield strength of CMSX-4.

It is also commonly understood that cyclic stress softening during high temperature fatigue in single crystal superalloys is associated with changes in the $\gamma$ ' precipitate morphology $[17,21]$. Coarsening and coalescence of the $\gamma^{\prime}$ precipitates results in a net increase in $\gamma$ channel width, which facilitates dislocation glide in the $\gamma$-matrix due to a reduction in Orowan stress. Since $\gamma$ ' coarsening occurs by diffusion, it is thought that the kinetics of this process depends on $\gamma-\gamma$ ' lattice mismatch and $\gamma$-matrix chemical composition and is also accelerated by plastic deformation [22]. Therefore, due to reduction in Re content, cyclic stress softening behaviors in alloys LSC-11 and LSC-15 are faster than in CMSX-4 under N-D and CD conditions, which corresponds with microstructural evolution as shown in Figure 5. Another contributing factor could be that alloys LSC-11 and LSC-15 have a larger $\gamma-\gamma$ ' lattice misfit than CMSX-4 [23].

During N-D fatigue tests, because the yield strengths of alloys LSC-11 and LSC-15 are lower than CMSX-4, larger plastic strains resulted. Hence, during loading reversal, the plasticity that occurred during the first half of the loading cycle was partially reversed by plasticity in tension, which reduced the kinematic hardening of the material during subsequent fatigue cycles. This caused the mean stress to reduce to nearly zero during N-D fatigue tests. The greater extent of plasticity during cycling led to faster relaxation of the mean stress (kinematic hardening). The larger plastic strain ranges in the LSC-11 and LSC-15 resulted in lower fatigue life than CMSX-4.

During C-D fatigue, however, creep strain accumulated during the dwell periods, which added to the yielding plastic strain. This accelerated relaxation of the mean stress even faster than N-D fatigue, and it eventually shifted to a positive mean stress. In the C-D fatigue tests, the cyclic stress amplitude and mean stress in the three alloys are comparable, and therefore their lives are also comparable, even though CMSX-4 still retained a slight advantage.

The $\gamma$ - $\gamma$ ' microstructures in N-D fatigue specimens after fatigue testing showed that the $\gamma$ ' precipitates coarsened and coalesced without a preferred orientation. Similar isotropic coarsening behaviour in single-crystal superalloys has been reported to occur under static annealing at elevated temperatures without applied stress [24] and under fully reversed strain-controlled isothermal fatigue loading [17,21]. It is interesting that the zero-compression $\mathrm{N}-\mathrm{D}$ fatigue loading conditions used in the present investigation did not promote directional coarsening in spite of being unbalanced, i.e. the strains were not fully reversed. It is well established that formation of $\gamma-\gamma$ ' rafts under creep loading is favored under high temperature and low-stress conditions. For N$\mathrm{D}$ fatigue loading, the rapid relaxation of the compressive mean stress resulted in cyclic stress-strain behaviour that appears fully reversed in the stress space, which could account for the nondirectional coarsening of the $\gamma$ ' precipitates.

For C-D loading, the $\gamma^{\prime}$ precipitates directionally coarsened forming discontinuous p-type rafts. Yablinsky and colleagues [10] have reportedly observed similar discontinuous p-type rafts in René N5 single crystals tested under zero-compression dwell fatigue at $1100^{\circ} \mathrm{C}$. It has been established from previous studies that the formation of p-type rafts occurs in alloys with a negative $\gamma-\gamma$ ' misfit, when subjected to a compressive stress applied along [001]. The compressive external stress causes an imbalance in the coherency stresses between the vertical and horizontal $\gamma$ channels. The resulting strain gradient causes directional coarsening via diffusion. It is suspected that the directional $\gamma^{\prime}$ rafts mostly formed during the compressive dwell periods. The development of discontinuous $\gamma$ ' rafts suggests that dislocation activities occurred in both the vertical and horizontal $\gamma$ channels under C-D fatigue loading.

Post test fractographic analysis of secondary fatigue cracks showed that fatigue cracks formed from regions of localized surface oxidation attack, i.e. oxide spikes (Figure 7b). This observation suggests that fatigue life under N-D and C-D fatigue at high temperature was controlled by fatigue and oxidation via a mechanism involving repetitive fracture and reformation of the oxide layer. Initially, high temperature exposure results in the formation of thin and protective oxide layer on the specimen surface. The surface oxide layer was accompanied by an adjacent layer in the substrate material that was depleted of $\gamma$ ' precipitates, which contributed to the formation of the surface oxide layer. After the oxide layer reached some critical thickness, tensile stresses imposed during fatigue cycling caused the oxide layer to crack. An oxide layer then reformed on the exposed substrate material. As this process repeats, oxidation was channeled into the substrate material forming oxide spikes. Oxidation cracking would be more likely to occur under higher tensile stresses by this mechanism and could account for the apparent success in correlating N-D and C-D fatigue lives using the mid-life maximum tensile stress (Figure 4c).

Higher tensile stresses were developed during C-D fatigue than $\mathrm{N}$ $\mathrm{D}$ fatigue. The fatigue lives of $\mathrm{C}-\mathrm{D}$ fatigue loading is much shorter than N-D not only due to increased elapsed time at high temperature, which increases environmental (oxidation) damage, but also due to creep deformation during the compressive hold period, which caused a positive mean stress in the hysteresis behavior. The positive mean stress during C-D fatigue contributes to higher tensile stresses, which facilitates cracking of the oxide layer. Differences in oxidation kinetics for the three alloys considered in this investigation may also partially account for the apparent differences in N-D and C-D fatigue lives. However, further study of the oxidation behaviour of LSC-11, LSC-15 and CMSX-4 would be necessary to quantify the oxidation kinetics of these alloys and to determine what effect this may have on N-D and C-D LCF lives. 


\section{Conclusions}

The isothermal zero-compression fatigue behaviour of reduced rhenium (LSC-11) and rhenium free (LSC-15) and CMSX-4 $(3 \mathrm{wt} \% \mathrm{Re})$ single-crystal alloys was investigated at $1100^{\circ} \mathrm{C}$ in air and with or without dwell in compression. CMSX-4 exhibited the highest cyclic stress amplitude and the best fatigue resistance under N-D loading condition, owing to its higher Re content.

The cyclic stress-strain behavior of N-D compressive fatigue relaxed to a nearly zero mean stress, while the C-D condition promoted a positive mean stress, due to accumulation of creep strain during the dwell periods.

The $\gamma-\gamma^{\prime}$ microstructure of all alloys under the N-D test conditions evolved into isotropic (non-directional) coarsening of the $\gamma$ ' precipitates, whereas the C-D test condition resulted in the formation of discontinuous $\gamma^{\prime}$ rafts parallel to the loading direction. The degree of $\gamma^{\prime}$ coarsening was greater in low-Re and Re-free alloys than in CMSX-4.

The N-D fatigue behavior of LSC-11 and LSC-15 were comparable, even though the low-Re alloy LSC-11 exhibited slightly higher compressive yield strength. All the alloys were compressive dwell sensitive, resulting in comparable C-D fatigue life, even though CMSX-4 had a slight advantage. Oxidation was thought to be a significant life-limiting factor, particularly under C-D conditions. Therefore, the fatigue life of N-D and C-D can be rationalized by a stress-life relationship.

\section{References}

1. A.D Cetel, and D.N. Duhl, "Second-Generation Nickel-Base Single Crystal Superalloy," Superalloys 1988, ed. S. Reichman et al. (Warrendale, PA: The Minerals, Metals and Materials Society, 1988), 235-244.

2. K. Harris et al. "Development of The Rhenium Containing Superalloys CMSX-4 and CM 186 LC for Single Crystal Blade and Directionally Solidified Vane Applications in Advanced Turbine Engines," Superalloys 1992, ed. S.D. Antolovich et al. (Warrendale, PA: The Minerals, Metals and Materials Society, 1992), 297-306.

3. C.S. Wukusick, and L. Buchakjian, U.K. Patent Appl. GB2235697. "Improved Property Balanced Nickel-base Superalloys for Producing Single Crystal Articles" - René N5, 1991.

4. W.S. Walston et al. "Rene N6: Third Generation Single Crystal Superalloy," Superalloys 1996, ed. R. D. Kissinger, et al. (Warrendale PA: The Minerals, Metals and Materials Society, 1996), 27-34.

5. G.L. Erickson, "The Development and Application of CMSX10," Superalloys 1996, ed. R. D. Kissinger, et al. (Warrendale PA: The Minerals, Metals and Materials Society, 1996), 35-44.

6. S. Walston et al. "Joint Development of a Fourth Generation Single Crystal Superalloy," Superalloys 2004, ed. K. A. Green, et al. (Warrendale PA: The Minerals, Metals and Materials Society, 2004), 15-24.
7. J.R. Li et al. "A Low-Cost Second Generation Single Crystal Superalloy DD6," Superalloys 2000, ed. T. M. Pollock, et al. (Warrendale PA: The Minerals, Metals and Materials Society, 2000), 777-783.

8. P. Caron, and T. Khan, "Development of a New Nickel Based Single Crystal Turbine Blade Alloy for Very High Temperatures," Advanced Materials and Processes Vol. 1, ed. H.E. Exner and V. Schumacher (Oberursel, Germany: DGM Informationsgesellschaft mbH, 1990), 333-338.

9. Akihiro Sato, private communication, IHI Corporation, 19 September 2010

10. C.A. Yablinsky et al. "Fatigue Behaviour in Monocrystalline Ni-Based Superalloys for Blade Applications," Superalloys 2008, ed. R. C. Reed et al. (Warrendale PA: The Minerals, Metals and Materials Society, 2008), 535-541.

11. E. Fleury and L. Remy, "Low Cycle Fatigue Damage in Nickel-Base Superalloy Single Crystals at Elevated Temperature," Materials Science and Engineering A, 167A (1) 1992, 23-30.

12. P.K. Wright, "Oxidation-Fatigue Interactions in a SingleCrystal Superalloy," ASTM STP 942, ed. H.D. Solomon, et al. (Philadelphia, PA: American Society for Testing and Materials, 1988), 558-575.

13. A. Epishin, et al. "Evolution of the $\gamma / \gamma^{\prime}$ Microstructure During High Temperature Creep of a Nickel-base Superalloy," Acta Materialia, 48 (16) 2000, 4169-4177.

14. R.C Reed, et al. "Creep of CMSX-4 Superalloy Single Crystals: Effects of rafting at high temperature," Acta Materialia, 47 (12) 1999, 3367-3381.

15. T.M. Pollock and A.S. Argon, "Directional coarsening in nickel-base single crystals with high volume fractions of coherent precipitates." Acta Metallurgica et Materialia, 42 (6) $1994,1859-1874$.

16. S. Kraft, R. Zauter, and H. Mughrabi, "Aspects of HighTemperature Low-Cycle Thermomechanical Fatigue of a Single Crystal Nickel-Base Superalloy," Fatigue and Fracture of Engineering Materials and Structures, 16 (2) 1993, 237-253.

17. T.P. Gabb, and G. Welsch, "The High Temperature Deformation in Cyclic Loading of a Single Crystal Nickelbase Superalloy," Acta Metallurgica, 37 (9), 1989, 25072516.

18. W.W. Milligan, E.S. Huron, and S.D. Antolovich, "Deformation, Fatigue and Fracture Behavior of Two Cast Anisotropic Superalloys," Fatigue '87 - Proceedings of the Third International Conference, ed. R. O. Ritchie and E. A. Starke, Jr., (West Midlands UK: Warley, 1987), 1561-1591.

19. V. Brien, and B. Decamps, "Low Cycle Fatigue of a Nickel Based Superalloy at High Temperature: Deformation 
Microstructures," Materials Science and Engineering A, 316A (1-2) 2001, 18-31.

20. M.S. Karunaratne, A.P. Carter, and R.C. Reed, "Interdiffusion in the Face-Centred Cubic Phase of the $\mathrm{Ni}-\mathrm{Re}, \mathrm{Ni}-\mathrm{Ta}$ and $\mathrm{Ni}-\mathrm{W}$ systems between 900 and $1300^{\circ} \mathrm{C}$," Materials Science and Engineering A, 281 (1-2) 2000, 229233.

21. P.D. Portella et al. "Cyclic Deformation of the Single Crystal Superalloy SRR 99 at $980^{\circ} \mathrm{C}$," Fatigue 96 - Proceedings of the 6th International Fatigue Congress, (Oxford UK: Pergamon Press, 1996), 795-800.

22. P. Caron, and O. Lavigne, "Recent Studies at Onera on Superalloys for Single Crystal Turbine Blades," Onera Aerospace Lab Journal, (3) Nov. 2011, 1-14.

23. Nobuyasu Tsuno, private communication, IHI Corporation, 7 February 2012.

24. H. Mughrabi, " $\gamma / \gamma$ ' Rafting and its Effect on the Creep and Fatigue Behavior of Monocrystalline Superalloys," The Johannes Weertman Symposium, ed. R.J. Arsenault, et al. (Warrendale PA: The Minerals, Metals, \& Materials Society, 1996), 267-278. 